\title{
FORMAÇÃO DE PROFISSIONAIS DE EDUCAÇÃO INFANTIL: EXPERIÊNCIAS DE ESTÁGIO SUPERVISIONADO
}

\author{
FORMACIÓN DE PROFESIONALES DE EDUCACIÓN INFANTIL: EXPERIENCIAS \\ DE PRÁCTICAS SUPERVISADAS
}

\section{INFANT EDUCATION PROFESSIONAL FORMATION: SUPERVISED TRAINING EXPERIENCES}

\author{
Virginia Georg SCHINDHELM ${ }^{1}$ \\ Maria Luisa Furlin BAMPI ${ }^{2}$
}

RESUMO: O trabalho objetiva refletir sobre nossa experiência como professoras do estágio supervisionado obrigatório do curso de Pedagogia da Universidade Federal Fluminense, compreendido como um campo de conhecimentos que supera a tradicional atividade prática instrumental. Aluno(a)s deparam-se com realidades cotidianas nas escolas de Educação Infantil onde vivem a ruptura teoria/prática necessária como área formativa de estudos e construções educacionais. Destacamos Japiassu e a pedagogia da incerteza porque rompe com dogmas e verdades absolutas no processo educativo, dialogamos com Vygotsky e a ênfase na compreensão dos sentidos e significados de vivências e com Nóvoa sobre a atividade docente e a reflexão sobre as práticas. Os autores e suas teses nos ajudam a entender a formação docente como um campo epistemológico.

PALAVRAS-CHAVE: Formação docente. Estágio supervisionado. Educação infantil.

RESUMEN: El trabajo tiene como objetivo reflexionar sobre nuestra experiencia como profesores de las prácticas supervisadas obligatorias en el curso de Pedagogía de la Universidad Federal Fluminense, que se entiende como un campo de conocimiento que supera la tradicional actividad práctica instrumental. Los/las estudiante/s se enfrentan a realidades cotidianas en las escuelas de Educación Infantil en las que la ruptura teoría/práctica necesaria como espacio formativo de estudios y construcciones educativas. Ponemos énfasis en Japiassu y la pedagogía de la incertidumbre porque rompe con dogmas y verdades absolutas en el proceso educativo, dialogamos con Vygotsky y el énfasis en la comprensión de los sentidos y significados de vivencias y con Nóvoa sobre la actividad docente y la reflexión sobre las prácticas. Los autores y sus tesis nos ayudan a entender la formación docente como un campo epistemológico.

PALAVBRAS-CLAVE: Formación docente. Prácticas supervisadas. Educación infantil.

\footnotetext{
${ }^{1}$ Universidade Federal Fluminense (UFF), Santo Antônio de Pádua - Rio de Janeiro - Brasil. Professora adjunta no Departamento de Ciências Humanas (PCH). ORCID <https://orcid.org/0000-0002-7259-9169>. Email:psicovir@terra.com.br

${ }^{2}$ Universidade Federal Fluminense (UFF), Santo Antônio de Pádua - Rio de Janeiro - Brasil. Coordenação Acadêmica do Ensino Superior. ORCID <https://orcid.org/0000-0003-1919-0230>. E-mail: luisa.bampi@uol.com.br
} 
ABSTRACT: The goal of this work is to reflect our experience as teachers in a compulsory supervised training in Pedagogy course at Federal Fluminense University, which is a knowledge field that overcomes the instrumental traditional activity practice. Students face the interruption between theory/practice which is necessary as a formative area in educational studies and constructions in everyday school realities in Infant Education, where they live. We emphasize Japiassu with his uncertain pedagogy which breaks doctrines and absolute facts in the educational process, talk to Vigotsky and his emphasis in the meaning understandings and the existance meanings and also with Nóvoa about the teaching activity and the practices of reflexion. Authors and their thesis help us understand the teaching formation as an epistemological field.

KEYWORDS: Teachers' degree. Supervised training. Infant education.

\section{Introdução}

O trabalho sobre o qual faremos algumas reflexões é resultado de nossa experiência como professoras de uma disciplina do curso de Pedagogia da Universidade Federal Fluminense sobre estágio supervisionado, quando alunos e alunas saem do âmbito acadêmico e deparam-se com realidades dos cotidianos nas escolas de Educação Infantil que elegeram para vivenciarem práticas e experiências num universo desconhecido e, muitas vezes, assustador pelas questões e experiências que vivenciam no dia a dia escolar.

No movimento de formação de sua carreira entendemos que todo profissional da Educação Infantil deveria conhecer mais profundamente sobre os campos da Educação, da Aprendizagem e do Desenvolvimento Infantil, entender a criança como sujeito social e da cultura, para que pudesse perceber-se e constituir-se em um(a) educador(a) mais apto(a) para os embates e exigências cotidianas (VASCONCELLOS, 2001).

No entanto, temos a clareza de que esses campos do conhecimento, assim como todos os outros também científicos, não se constituem como verdades definitivas ou mesmo portos seguros, conforme nos apontou Japiassu (1983, p. 13) ao postular "a instauração de uma pedagogia da incerteza, da insegurança e da provisoriedade, incapaz de parâmetros dogmáticos e absolutos [...]”.

Desejamos apresentar relatos trazidos por nosso(a)s estagiário(a)s, alunos e alunas da disciplina Pesquisa e Prática Pedagógica, que nos deram a oportunidade de discutir e refletir sobre teoria e prática na formação docente e também sobre a importância de uma formação continuada aos profissionais de educação. Estamos certas que "quem acredita em certas verdades científicas ou filosóficas como se fossem um porto seguro esconde, no fundo, um 
medo básico não superado e uma angústia não resolvida. Melhor ainda, faz delas um mito" (JAPIASSU, 1983, p. 13).

Nesse sentido, buscamos não apenas ensinar nossos futuros docentes a $\operatorname{ser}$ um(a) educador(a) infantil, mas também reaprender com eles que a vida real e produtiva exige criatividade e se baseia no confronto diário da crítica e autocrítica de um compromisso entre o fatual e o possível (ibidem, p. 15).

De modo a nortear nosso trabalho com o(a)s estagiário(a)s, partimos de alguns questionamentos iniciais:

- as aprendizagens fundamentais à docência na Educação Infantil vinculam-se a quê?

- onde pretendemos chegar, como supervisoras de estágios, ao observamos propostas e práticas pedagógicas descontextualizadas, empobrecidas e sem intencionalidade clara?

Frente às questões declaradas, nosso artigo organiza-se em duas sessões onde entrelaçamos postulados teóricos, relatos de nosso(a)s aluno(a)s e nossas reflexões sobre as contribuições que um estágio supervisionado pode oferecer para a formação do(a) futuro(a) profissional de Educação Infantil sem deixar de admitirmos que "é muito doloroso descobrirmos ou reconhecermos os limites de nosso pensamento", na medida em que vivemos cotidianamente o drama da incerteza e da insegurança diante do mito do porto seguro e sua ideia sempre escondida de que toda produção intelectual seria genial ou poderia perdurar para sempre, segundo Japiassu (1983, p. 15).

\section{Estágio e formação docente: um campo epistemológico}

Entendemos que alunos e alunas em processo de formação docente deveriam vincular suas aprendizagens acadêmicas e pessoais às especificidades e às singularidades das crianças, com ênfase nas dimensões dos cuidados/educação com/dos pequenos e naquelas que se referem ao desenvolvimento físico, emocional, afetivo, cognitivo e sociocultural.

Nosso(a)s estagiário(a)s observaram inúmeras vezes nas atividades vivenciadas nas escolas que as propostas sugeridas num momento de intervenção eram desconsideradas, levando-os ao sentimento de incapacidade para fazer, criar, inventar e reinventar práticas educativas. "Eu achava que estava tendo uma boa formação; agora, estou chocada com a realidade daquelas crianças, e nem sei por onde começar. Na prática a teoria é outra" relatou uma de nossas alunas.

Uma questão que sempre nos deixou sensibilizadas diz respeito ao olhar e sentimento de graduando(a)s sobre seus cursos como teóricos e bem distantes da profissão docente que 
"só se aprende na prática". Alguns se referem a certos professores e disciplinas como "só teóricos, mas quando vamos estagiar vemos que prática e teoria não se encontram". Então, diante de situações novas, vivem uma ruptura, deparam-se com a realidade onde só o domínio das Ciências da Educação não são suficientes. Com isso, o(a)s aluno(a)s argumentam que a universidade está distante da realidade e parece que o mundo real e o mundo acadêmico convivem paralelamente.

Japiassu (1983, p. 16) já nos alertava há longo tempo que "o aluno ingressa na universidade com uma série de estereótipos que se devem, pelo menos em parte, à própria universidade e a seu corpo de professores". Um desses estereótipos é a ilusão do professor apresentar-se aos alunos como porto seguro que lhes ensina ou transmite "a própria verdade ou, então, a verdade de um autor que lhe serve de muleta intelectual" (ibidem). Essa pedagogia não forma pesquisadores de verdade, assegura o autor, mas reduz a educação a um mero ensinar o já sabido, transmitir o já estabelecido ou mesmo reproduzir o já produzido. Seria esse mesmo o nosso papel ou a nossa função como professoras supervisoras de estágios?

Frente a essa questão, evidenciamos que a reprodução de práticas no cotidiano escolar infantil se faz muito mais presente do que as discussões e o desejo de aprimoramento vislumbrados nos cursos de formação docente, dentre eles, a Pedagogia.

No entanto, fazemos um esforço para levar o(a)s estagiário(a)s a compreender a relevância dos estágios curriculares, na medida em que, por meio deles, os/as futuros/as professores/as têm a possibilidade de vivenciar teorias estudadas e práticas pedagógicas articulando-as aos seus cursos de formação num valioso intercâmbio de conhecimentos teóricos e práticos (GUIZZO, FELIPE, 2012). Sendo assim, os estágios precisam ser apresentados aos graduandos como espaços de formação, que possibilitam estudos e interpretações de realidades educacionais em futuras áreas de atuação. Reitera Japiassu (1983, p. 17) que:

[...] constitui tarefa do educador provocar nos alunos desequilíbrios ou necessidades psicológicas, desejo de pesquisa, espírito de busca, sede de descoberta. Porque a ação educativa sempre supõe a reforma de uma ilusão, um processo contínuo de retificação das ilusões perdidas.

Na busca por construir nossos conhecimentos sobre a prática de nosso(a)s aluno(a)s nos cenários de seus estágios, elegemos para as nossas reflexões a perspectiva sócio histórico cultural de Vygotsky por meio da qual buscamos sempre compreender os sentidos e os significados de todos os artefatos culturais que escolas e crianças constantemente consumiam, 
ressignificavam, transformavam e reinventavam e teciam individual e coletivamente nas múltiplas redes de saberes, valores, sentimentos e pensamentos. Artefatos culturais são entendidos como produtos/instrumentos criados e desenvolvidos pelo ser humano, como espécie diferenciada das demais, para transformar por meio de ações a natureza. Torna-se assim, um elemento interposto entre o homem e o objeto de seu trabalho, constituído por meio de ideologias ou políticas, num processo privilegiado de relações homem/mundo (OLIVEIRA, 1997). Assim, qualquer cenário inserido na sociedade humana precisa ser visto e compreendido como uma totalidade em constante transformação, num sistema dinâmico e contraditório em processo de mudança, em processo de desenvolvimento. "Assim como todo homem vive diariamente o problema da incerteza e da insegurança, também os cientistas vivem o mesmo drama", sustenta Japiassu (1983, p. 15). Afinal, a ciência é um fenômeno social como outro qualquer e sua organização e seus membros se submetem aos mesmos parâmetros sociais, completa o autor (ibidem).

Frente a isso, tomar contato com o cotidiano, implica em participar de uma realidade impactante, apreendida pelo sujeito sem julgamento prévio (TOASSA, SOUZA, 2010). Nesse sentido, o conceito de vivência relaciona o sujeito, em suas características pessoais, ao meio em que se encontra; negativas ou positivas, as vivências são singulares e revestidas de um caráter irracional marcado por sentimentos e sensações que demandam compreensão após vivenciadas (ibidem, 2010).

Questionamo-nos, então, como acolher as percepções singulares das vivências de nosso(a)s estagiário(a)s nos cotidianos escolares? Como transformar essas vivências em experiências pessoais e acadêmicas que possam contribuir no processo de formação desse(a)s futuro(a)s docentes?

Além das atividades da sala de aula há nos estágios a necessidade de desenvolver atividades não só relativas à docência, mas também à gestão educacional, com possibilidades de produzir uma avaliação dessa experiência e sua autoavaliação (DCN - Curso de Pedagogia/2005). Refere-se a uma demanda de atender todo o processo paralelo à sala de aula que ocorre nas instituições escolares. O sistema de gestão das informações de documentação de alunos e atenção às diretrizes curriculares dos processos pedagógicos, as respostas às instituições reguladoras da educação MEC, Secretarias de Educação, dentre outras. Além disso, torna-se ainda necessário compreender o projeto pedagógico daquela escola e adentrar na filosofia de cada instituição escolar, cada uma com uma cultura e com direcionamentos específicos, sem deixar de mencionar as rotinas de planejamento, as reuniões, os calendários, dentre outros. 
Também destacamos a perspectiva sócio histórico cultural e a compreensão do que a escola apresenta como valor institucional, desde a sua representação naquela comunidade: como foi fundada? Quem são os professores? Como são organizados os espaços físicos? Acreditamos que as mediações culturais compreendem muito mais do que as teorias que se apresentam aos futuros docentes.

Nossa prática como professoras na Educação levou-nos a compreender o estágio como um campo de conhecimentos, o que significa atribuir-lhe um estatuto epistemológico que supera sua tradicional redução à atividade prática instrumental. E, enquanto campo de conhecimentos, produz-se na interação dos cursos de formação com o campo social no qual se desenvolvem as práticas educativas. Nesse sentido, o estágio constitui-se ainda em atividade de pesquisa. Japiassu (1983) nos orienta sobre o empenho em formar a inteligência de nossos alunos utilizando a ação pedagógica com o objetivo de promover, inventar ou reinventar nossa cultura, encarnando assim o poder do conhecimento e da reflexão crítica.

Ora, o pensamento é um trabalho, nas palavras do autor. Não se limita a uma mera apropriação de dados empíricos ou conceituais. Sua tarefa fundamental consiste em transformar o não-sabido num saber produzido, em transformar o saber do senso comum, da experiência imediata, num saber mediatizado pela reflexão [...] Se temos que ensinar algo a nossos alunos, que lhes ensinemos a pensar, que lhes ensinemos a aprender, a se construírem e a se reconstruírem, a fazerem perguntas e a questionarem, o já sabido (JAPIASSU, 1983, p. 17).

Mediante essa argumentação, consideramos um estágio curricular supervisionado como um momento de aproximação com a realidade escolar, onde o/a aluno(a), futuro(a) professor(a), pode praticar as teorias aprendidas ao longo do curso, buscando uma relação entre a teoria e a prática. Entendemos ainda como fundamental e prioritário que esse seja um dos principais momentos para conhecer o ambiente em que futuramente irá atuar.

Relevante se torna considerar o postulado de PIMENTA (2008, p. 70) quando alerta que não se deve “[...] colocar o estágio como o polo prático do curso, mas como uma aproximação à prática, na medida em que será consequente a teoria estudada no curso, que por sua vez, deverá se constituir numa reflexão sobre e a partir da realidade da escola [...]".

Em consonância com a autora, Nóvoa (2011) defende que o contato com o contexto da atividade docente precisa ser tomado como um campo de reflexão sobre as práticas, especialmente, os primeiros anos de atividades na docência. Os profissionais da educação como a pedagogia e as licenciaturas, similar a outras profissões, antes de exercerem suas atividades de forma autônoma são acompanhados, orientados, ou mesmo fazem residência. 
Contrariamente aos profissionais da docência que no último ano do curso procuram um local, nem sempre uma escola, e, com muita dificuldade, realizam um estágio que é apresentado a um orientador, que lê. Por vezes apenas lê e o avalia no último semestre, por ocasião da conclusão do curso, sem uma reflexão sobre as questões que são descritas. Quando há espaço para reflexão é em um encontro ou outro durante o semestre que antecede o final do curso no qual o estagiário é "lançado" na sala de aula. Esse distanciamento entre o fazer e a universidade se manifesta com seus orientadores que, muitas vezes, desconhecem a realidade da escola.

Segundo Pimenta (2008), o estágio é um componente curricular com um campo de conhecimento próprio e um momento investigativo, levando a uma reflexão e intervenção. Sua finalidade é colaborar no processo de formação de educadores/as, para que haja compreensão e análise dos espaços de atuação, a partir de uma inserção profissional crítica, transformadora e criativa. O estágio servirá para que o aluno se localize e reconheça o espaço escolar como seu futuro campo de atuação e para que comece a formar sua identidade docente. $\mathrm{O}$ curso, as disciplinas e as experiências adquiridas ao longo da graduação, tudo isso, deve convergir para o estágio curricular supervisionado, é a hora de se colocar na posição de professor, momento de deixar de lado as incertezas e partir para a ação docente.

Concordamos com Krug (2008) que o estágio deve ser [...] concebido como uma experiência, ou seja, como um conjunto de vivências significativas através das quais o estagiário identifica, seleciona, destaca os conhecimentos necessários e válidos para a sua atividade profissional.

Ressaltamos com nosso(a)s aluno(a)s a importância de viverem um estágio como um processo de construção reflexiva, na medida em que se constitui como uma vivência com aspectos capazes de incitar a dúvida e de fornecer pistas que estimulem seus processos de autoria. Por sua vez, pode, também, favorecer a construção de conhecimentos que possam explicar as contradições próprias do nosso tempo no campo educacional sem, no entanto, deixar de estar ciente do que nos alerta Japiassu (1983):

[...] o educador não é alguém que detém ciumentamente o monopólio da verdade sobre determinado setor do conhecimento. Muito menos ainda, alguém que procura impor sua verdade aos outros, pois não possui uma concepção da verdade como fórmula universal. A verdade do conhecimento é uma procura e não uma posse, assegura o autor (ibidem, p. 43). 
Além disso, as atividades de estágios mostram-se como momentos de compartilhamento entre teorias e práticas, tanto para os/as alunos(a)s estagiário(a)s, como para os/as docentes que o/as supervisionam. Nesta perspectiva, ambos terão a oportunidade de dar sentido e significado a sua profissão, constituindo um processo de aprendizagem que é contínuo e intrínseco à ação e à formação docente, em face das exigências e dos desafios impostos na contemporaneidade. Assim, [...] o estágio passa a ser um retrato vivo da prática docente e o professor-aluno terá muito a dizer, ensinar, a expressar sua realidade e a de seus colegas de profissão [...] (PIMENTA, LIMA, 2008, p. 127).

Nesse espaço dialético entre estagiário(a) e orientador(a) o que dizem o(a)s aluno(a)s de suas práticas? O próximo item explora algumas questões sobre esse caleidoscópio que é o cotidiano de uma escola de educação infantil.

\section{Estágios: por uma vivência que supere a imitação de modelos.}

Como nos diz Vygotsky (1991), a estrutura e o funcionamento das funções superiores da mente humana é produto de processos construídos nas ligações entre a história individual do sujeito e a história social, não como um ser passivo, mas em uma relação dialética regida pelo processo de internalização. Tal processo ocorre inicialmente fora do indivíduo (interpsicológico), como é o caso da linguagem e da cultura e, posteriormente, internamente, por um processo intrapsicológico. Assinala-se que a internalização envolve uma série de transformações, abarcando a interatividade desse sujeito com os conhecimentos e instrumentos passados e os presentes que o constituem, além de fazer projeções futuras.

Inspiradas nos aportes de Vygotsky (1991) defendemos a prática do estágio enquanto um processo para além do estagiário em campo apenas para a observação passiva, mas como um campo de estudos que potencializa o conhecimento do sujeito.

Segundo Nóvoa (2011), um profissional se faz pela reflexão sobre sua prática, não apenas pela prática, assim precisamos de experiências enquanto ato coletivo para ir produzindo um saber docente de consciência pedagógica, de partilha. Isto é, um professor precisa não apenas saber matemática para se tornar professor. Mais do que isso é necessária a capacidade de compreensão e de dar sentido aos conhecimentos matemáticos na relação com a docência.

Destacamos o exemplo de um trabalho desenvolvido pelos alunos em uma escola de Educação Infantil localizada em Niterói, na comunidade chamada Caramujo. Conta com infraestrutura invejável, mas o local é dominado pelo tráfico e representa um risco para todos. 
Foi narrado um projeto para os pequenos de resgate à história do bairro: A história do bairro, contada por uma mãe. O bairro chamava-se Vila Verde porque tinha muitas árvores, nele corria um rio chamado Caramujo. Atualmente o nome do rio dá o nome à comunidade. $\mathrm{O}$ conhecimento da história daquele contexto social oferece um referencial diferente para os pequenos e quem sabe de transformação das imagens de morros com casas suspensas, muito lixo, representadas nos desenhos que fazem...

Da mesma forma que compartilhamos as experiências daqueles que fazem parte da história da comunidade, devemos cuidar dos novos professores, como defende Nóvoa (2011). Afirma que é no seio, no coração da profissão, no fazer docente, que devemos promover uma cultura mais partilhada por meio de equipes de supervisão, tutoria, etc., para assim o professor gradativamente obter os saberes necessários ao exercício da profissão. Somente assim tornase autor de suas propostas, problematizando aquilo que enquanto participante ativo leva para o cotidiano das orientações e discussões de modo a promover a articulação teórica e prática para a compreensão dos processos e mediações evidenciadas no fazer pedagógico em um contexto social e cultural de organização e desenvolvimento docente, como assinala Vygotsky (1991)

Para o autor, o homem estabelece com o mundo uma relação indireta, mediada por signos e instrumentos criados por si próprio. Destaca-se que, na contramão da perspectiva de apenas uma adaptação aos conhecimentos socialmente construídos, precisamos estabelecer com os discentes um processo de reflexão sobre as práticas e as mudanças sociais que a sociedade e a escola se apresentam aos nossos estagiários, distinta de um processo escolar no qual são propostos a resolver problemas padronizados, como refere o autor (VIGOTSKY, p. $88)$.

Além disso, assinala Nóvoa (2011), a universidade precisa institucionalizar o espaço onde se construam as práticas da pedagogia do isomorfismo, que se faça na universidade exatamente aquilo que diz que se deve fazer na prática, na escola. Temos que inventar o lugar de produção de profissão no qual deve haver coerência, onde se vai produzindo a docência.

Como nos disse uma aluna: "muitos são os professores que possuem um discurso muito diferente de suas práticas. - Dizem que devemos ser sensíveis aos nossos alunos, no entanto, esse mesmo professor não é com a gente”. (Diário das aulas, citação da aluna, agosto/2014).

Frente a essa observação, destacamos que não há como pensar a escola que recebe estagiário(a)s numa dinâmica de relações em que o professor orientador entenda a licenciatura enquanto um projeto coletivo menos verticalizado. Torna-se fundamental pensar e refletir 
sobre as práticas para que sejam mais colaborativas, de um trabalho que não privilegie o trabalho solitário do professor na sala de aula de modo verticalizado porque esse modelo repetirá a docência da mesma forma na educação infantil.

Diante desse cenário questionamos: por que os discentes do curso de Pedagogia que, mesmo após terem debruçado seus estudos no aperfeiçoamento teórico, continuam repetindo modelos? E ainda, como o estágio, no curso de Pedagogia, poderia possibilitar uma superação desse trabalho pedagógico docente? O problema torna-se ainda maior quando nos deparamos com discentes egressos do curso de Pedagogia e temos a sensação de não os reconhecer. Evidenciamos nesse sentido que a reprodução de práticas se faz muito mais presente que as discussões e o desejo de aprimoramento vislumbrado no curso de Pedagogia. Uma das nossas hipóteses é que, quando chegam ao campo de trabalho, os modelos são mais fortes e impressos de tal modo na realidade que os novos professores, ao invés de questioná-los, os repetem.

Um formato de estágio pautado na imitação de modelos, como apontam Pimenta e Lima (2004):

O estágio, nessa perspectiva, reduz-se a observar os professores em aula e imitar os modelos, sem proceder a uma análise crítica fundamentada teoricamente e legitimada na realidade social em que o ensino se processa. Assim, a observação, se limita à sala de aula, sem análise do contexto escolar, e espera-se do estagiário a elaboração e execução de "aulasmodelo". (PIMENTA e LIMA, 2004, p. 36).

Em resposta às questões que privilegiam a teoria em detrimento da prática, ou ao contrário, que privilegiam a prática ao invés da teoria, concluímos em consonância com Nóvoa (2011), que a formação do professor não deve assumir e responder à dicotomia, porque ambas são importantes. Não devemos nos fechar em nenhuma das extremidades seja da teoria ou da prática, porque falar de qualquer profissão é afirmar a importância das duas dimensões, as teóricas e as práticas.

Os professores são aqueles que podem melhorar a educação. Para isso, devem exercitar uma análise constante dos seus saberes e fazeres.

\section{Considerações finais}

O tema estágio e prática, assim como construção de conhecimentos a partir dessa vivência, desencadeia muitas inquietações. Cabe lembrarmos que construção dos saberes também está atrelada à criação, à invenção de novas formas de ensinar e aprender. Inovar é 
preciso, porém com prudência e responsabilidade, de modo a evitar prejuízos ao futuro profissional. Para que isso não aconteça, faz-se necessário a clareza de que não estamos desenvolvendo padrões ou mesmo fórmulas para o desenvolvimento dos estágios. A busca por melhorias e vontade de acertar costuma ser uma constante tanto para nós orientadoras como para nosso(a)s estagiário(a)s, sempre lembrando que "[...] a vivência concreta na escola, o contato com as incertezas, as alegrias, os conflitos e os sonhos se traduzem em maior integração entre professores e alunos", conforme aprendemos com Pimenta e Lima (2008, p. 243).

Nessa perspectiva, persistimos sobre a importância do desenvolvimento dos estágios nos espaços escolares e não escolares, garantindo não apenas uma boa relação pedagógica entre docentes e discentes, no ingresso da experiência profissional dos/as futuros/as licenciados/as, mas também colaborando para que esses docentes construam-se como cientistas e pensadores distanciados de dogmatismos, de verdades absolutas e de saberes definitivos que evidenciem uma ciência da educação em estado de agonia. Japiassu (1983, p. 20) nos alertou que "não pode haver verdade absoluta no domínio do conhecimento humano, no sentido que seria o ponto final, o ponto de perfeição do conhecimento". Porque ela é sempre uma etapa de um processo de constante aproximação. Ou, em outras palavras, a verdade é uma realidade histórica, relativa, que nos leva a admitir a provisoriedade de todo e qualquer modelo explicativo.

Cabe a nós a formação de formadores sem pensar na dimensão humana? Impossível se torna desconsiderar um processo formativo como uma construção consciente que ocorre no contato, nas experiências práticas, na vivência e convivência cotidiana com os Outros sociais. Resgatamos Vygotsky quando nos ensina sobre as formações afetivas nas vivências mais complexas pelas quais podemos utilizar e até mesmo compreender nossos estados passageiros de expressões singulares como fusões de pensamento, linguagem e emoção/afeto (TOASSA, SOUZA, 2010).

Nosso papel como professoras orientadoras também é garantir às/aos futuro(a)s professore(a)s o acesso à ciência e à cultura marcados pelas múltiplas vozes e pela interação com o Outro, como nos asseguram os postulados vygotskyanos.

Convidamos nosso(a)s leitore(a)s a repensar a formação docente enquanto um espaço para desenvolver a capacidade de construir sempre e ordenar os conhecimentos e as atividades pedagógicas, além da capacidade de compreendê-los como uma determinada ciência. Destacamos que, fundamental num processo formativo é a constância ininterrupta de construir e dar sentido aos conhecimentos. Para tal é também aconselhável criarmos na universidade 
espaços para vivências das práticas pedagógicas com as quais nosso(a)s estagiário(a)s se deparam nos cenários escolares da Educação Infantil. Temos que abrir e recriar o lugar da reflexão e análise sobre os fazeres e saberes pedagógicos como um campo epistemológico de formação para professore(a)s. Afinal, "uma das funções de todo conhecimento humano consiste em delimitar o campo do possível, não em fixar a ideia de uma verdade intangível e eterna", nas palavras de (JAPIASSU, 1983, p. 23).

\section{REFERÊNCIAS}

GUIZZO, Bianca.; FELIPE, Jane. Legislação e políticas públicas para a Educação Infantil: articulações com a formação docente, Revista Brasileira de Política e Administração da Educação, v. 28, n. 3, set./dez. 2012.

JAPIASSU, Hilton. A pedagogia da incerteza e outros estudos. Rio de Janeiro: Imago, 1983.

KRAMER, Sonia.; CORSINO, Patricia.; NUNES, Maria Fernanda. Infância e crianças de 6 anos: desafios das transições na educação infantil e no ensino fundamental. São Paulo: Educação e Pesquisa. v. 37, n. 1, 220 p. 69-85, jan./abr. 2011.

KRUG, Hugo Norberto et al. Estágio Curricular supervisionado em Educação Física: significado e importância sob a ótica dos acadêmicos do curso de licenciatura. Grupo de Estudos e Pesquisas em Educação Física (GEPEF/UFSM); apresentado no XXVII Simpósio Nacional de Educação Física, Pelotas - RS, 2008.

NÓVOA, Antonio. Como formar professores para o futuro. III Encontro PIBID, 2011, Disponível em: https://www.youtube.com/watch?v=KrR1aJ5A9Go. Acesso em: 11 jan. 2018.

OLIVEIRA, Marta Kohl de. Vygotsky. Aprendizado e desenvolvimento: um processo sócio-histórico. São Paulo: Scipione, 1997. (Pensamento e ação no magistério).

PIMENTA, Selma Garrido.; LIMA, Maria Socorro Lucena. Estágio e docência. São Paulo: Cortez, 2008.

TOASSA, Gisele.; SOUZA, Marilene Proença Rebello de. As vivências: questões de tradução, sentidos e fontes epistemológicas no legado de Vygotsky. Psicologia USP. São Paulo, v. 21, n. 4, 2010. Disponível em: www.scielo.br/scielo.php?pid=S0103$65642010000400007 \&$ script. Acesso em: 29 jan. 2018.

VASCONCELLOS, Vera Maria Ramos de. Formação dos Profissionais de Educação Infantil: reflexões sobre uma experiência. Revista Em Aberto, Brasília, v. 18, n. 73, p. 98-111, jul 2001. Disponível em: http://emaberto.inep.gov.br/index.php/emaberto. Acesso em: 26 abr. 2013.

VYGOTSKY, Lev Semenovich. Pensamento e Linguagem. São Paulo: Martins Fontes, 1991. 


\section{Como referenciar este artigo}

SCHINDHELM V. G.; BAMPI, M. L. F. Formação de profissionais de Educação Infantil: experiências de estágio supervisionado. Revista Ibero-Americana de Estudos em Educação, Araraquara, v. 14, n. 1, p. 280-292, jan./mar., 2019. E-ISSN: 1982-5587. DOI: 10.21723/riaee.v14i1.11099

Submissão: 28/02/2018

Revisões requeridas: $30 / 05 / 2018$

Aprovação final: 26/08/2018 